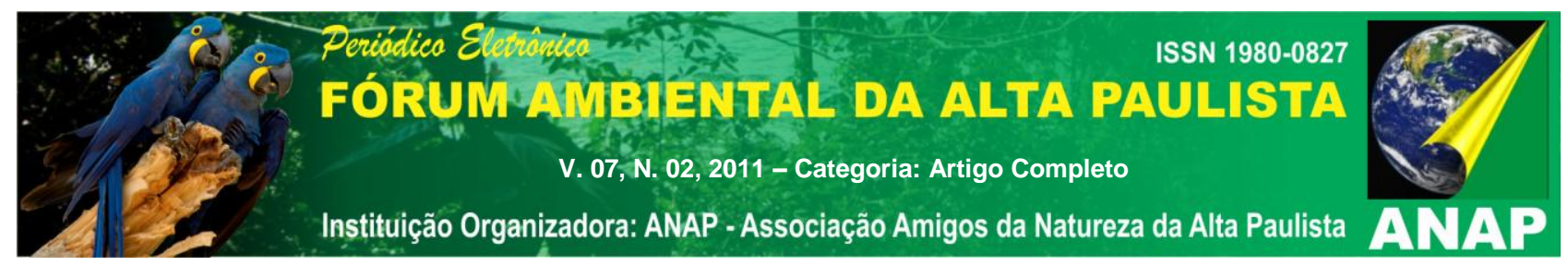

\title{
O REUSO DA ÁGUA PROPORCIONA COMPETITIVIDADE AO SETOR INDUSTRIAL
}

\author{
lara Aparecida dos Santos Oliveira ${ }^{1}$ \\ Cristiana Aparecida Portero Yafushi ${ }^{2}$ \\ Ival Leite Pimenta Júnior ${ }^{3}$ \\ Tatiene Martins Coelho ${ }^{4}$
}

Resumo: Com o objetivo de analisar como o reuso da água no setor industrial poderá contribuir para a preservação do meio ambiente e melhoria nos seus processos produtivos, o presente trabalho aborda o reuso da água como meio de obtenção de benefícios competitivos para o ramo. O crescimento desordenado do consumo, oriundo da Revolução Industrial e do aumento da população, trouxe consigo impactos negativos ao meio ambiente, poluindo rios, ar e solo, afetando assim a qualidade de vida no mundo, que necessita cada vez mais extrair recursos naturais para atender a demanda. Esse cenário despertou nas autoridades governamentais e na sociedade uma preocupação em relação aos impactos ambientais, que acarretou em uma pressão para as empresas emissoras de poluentes, no qual se tornou necessário formular medidas para otimizar a utilização dos recursos hídricos. O reuso da água, surge como uma das alternativas mais importantes para minimizar os impactos ambientais, possibilitando muitas vezes lucro para as empresas industriais, preservando assim a água potável para o consumo, que é essencial para a sobrevivência humana. O reuso da água proporciona um marketing positivo diante da sociedade, além de evitar o pagamento de possíveis indenizações, tornando as organizações mais competitivas. Assim as empresas do setor industrial devem escolher dentre as diferentes formas de reuso da água, aquela que melhor se adapte as suas atividades, proporcionando que essa prática seja efetuada em todos os seus processos.

Palavras-chave: Meio ambiente. Reuso da água. Competitividade do setor industrial.

\footnotetext{
${ }^{1}$ Graduanda em Administração pelas Faculdades Integradas de Bauru (FIB). iara_ap_oli@yahoo.com.br

${ }^{2}$ Graduanda em Administração pelas Faculdades Integradas de Bauru (FIB). cristianayafushi@gmail.com

${ }^{3}$ Graduando em Administração pelas Faculdades Integradas de Bauru (FIB). ivalpjr@ig.com.br

4 Professora Ms. dos cursos de Administração e Turismo nas Faculdades Integradas de Bauru (FIB). tatyene@terra.com.br
} 


\section{INTRUDUÇÃO}

As questões ambientais atingem níveis cada vez mais amplos da sociedade mundial, pois a preocupação com a escassez dos recursos naturais torna-se dever de todos.

De acordo com Philippi; Roméro; Bruna (2004), a água é um recurso natural essencial, componente dos seres vivos ou meio de vida de várias espécies vegetais e animais, elemento representativo de valores socioculturais e fator de produção de bens de consumo e produtos agrícolas.

Em um mercado globalizado e competitivo, as organizações buscam por meio de boas práticas na gestão ambiental, adquirirem vantagens competitivas, adotando políticas diferenciadas com relação ao meio ambiente. Para Brito; Câmara (1998) a proteção dos recursos naturais é fundamental para a melhoria da qualidade de vida das presentes e futuras gerações.

O setor industrial utiliza grandes quantidades de água em seu processo produtivo que depois de utilizada é descartada nas redes de esgoto sanitário ou diretamente nos rios, proporcionando aumento da poluição das cidades. Dessa forma o reuso da água é uma opção para as empresas do ramo porque proporciona economia no valor a ser pago pelo produto no mês, evita o desperdício, contribui para a diminuição da poluição dos mananciais e aumenta a competitividade do setor, uma vez que os consumidores estão cada vez mais aptos a comprarem de empresas socialmente responsáveis. De acordo com USP (2010), reaproveitamento ou reuso da água é o processo pelo qual a água tratada ou não é reutilizada para o mesmo ou outro fim.

As empresas que reutilizam a água e praticam a gestão ambiental melhoram sua imagem diante dos clientes, fornecedores e sociedade de seu mercado de atuação, são mais competitivas, atuam em questões ambientais e adquirem benefícios econômicos.

Tendo em vista que a água é um recurso natural cada vez mais escasso, tornase necessário o estudo do reuso na indústria por ser um ramo de atividade que a utiliza 


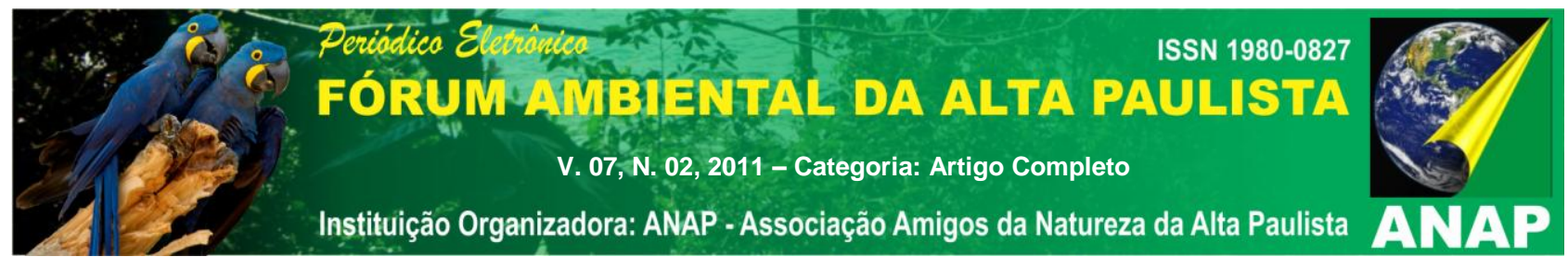

em grandes quantidades, onde na maioria das vezes é descartada em condições de ser reutilizada.

O objetivo é demonstrar como as empresas do setor industrial podem se beneficiar por meio do reuso da água em suas instalações, analisando algumas formas de reuso existentes e como essa técnica poderá agregar valores competitivos as empresas do ramo.

O trabalho foi baseado totalmente em pesquisas bibliográficas, tendo como fonte a opinião de vários autores, utilizando tanto material de acervo literário como eletrônico. Conforme Cervo; Bervian (2002), a pesquisa bibliográfica visa explicar um problema tendo como base às referências publicadas por outros autores, podendo ser realizada independentemente ou como parte de pesquisa descrita ou experimental. Busca conhecer e analisar as contribuições culturais ou científicas publicadas anteriormente, proporcionando assim um domínio sobre um determinado assunto, tema ou problema através da metodologia científica.

\section{O REUSO DA ÁGUA PROPORCIONA COMPETITIVIDADE AO SETOR INDUSTRIAL}

\subsection{A importância do reuso da água}

As reservas de água do planeta, segundo Dowbor; Tagnin (2005) são constituídas de $98 \%$ de águas salgadas e $2 \%$ de água doce, onde $87 \%$ estão bloqueadas nas calotas polares e nas geleiras, o restante se encontra em subterrâneos, na atmosfera e nos organismos vivos. Portanto as reservas de água são limitadas e em muitas regiões do mundo estão escassas.

As fontes de água são abundantes, porém mal distribuídas. O Brasil possui a maior disponibilidade hídrica do planeta com cerca de $13,8 \%$ do fluído médio mundial, totalizando $5.744 \mathrm{~km} 3 /$ ano, onde $68,5 \%$ estão localizados na região norte que possui cerca de $7 \%$ da população brasileira, $6 \%$ estão na região sudeste com $43 \%$ da população, $3 \%$ estão na região nordeste que habita $29 \%$ das pessoas (PHILIPPI; ROMÉRO; BRUNA, 2004). 


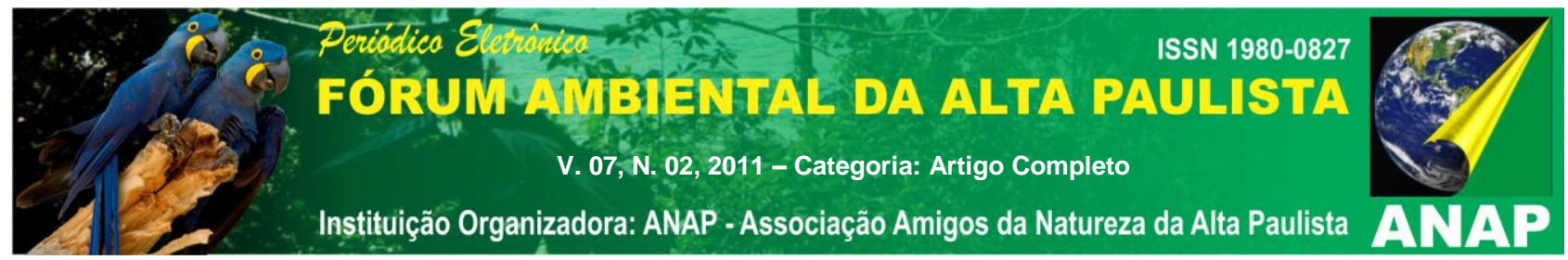

De acordo com Mancuso; Santos (2003), reuso da água é o aproveitamento de águas previamente utilizadas uma ou mais vezes em alguma atividade humana. Pode ser direto ou indireto, bem como decorrer de ações planejadas ou não planejadas. Por meio do reuso, as empresas podem adquirir água para a produção de vapor, lavagem de chaminés e processos industriais específicos como: manufatura de papel e papelão, indústria têxtil, de material plástico e de produtos químicos, petroquímicos, curtumes, construção civil, etc.

Ações como essas refletem diretamente na imagem das empresas, demonstrando a conscientização do setor com relação à preservação ambiental e responsabilidade social, aumentando a competitividade empresarial (FIESP, 2010).

Conservação da água para FIESP (2010) são práticas, técnicas e tecnologias que aperfeiçoam a eficiência de seu uso, podendo também ser definida como qualquer ação que: reduz a quantidade de água retirada das fontes de abastecimento, diminui o consumo e o desperdício de água, melhora a eficiência de seu uso, aumenta a reciclagem e evita a poluição da água.

Segundo FIESP (2010), é necessário a criação de estratégias para racionalizar a utilização dos recursos hídricos e minimizar a geração de efluentes pelas indústrias.

De acordo com Moura (2002), a água pode ser utilizada em vários processos na empresa antes de ser descartada definitivamente, evitando perdas, desperdícios e proporcionando redução no volume de água para as estações de tratamento.

Segundo SABESP (2010), a água de reuso não é potável, portanto não deve ser ingerida pelas pessoas apesar de sua aparência ser semelhante à potável.

De acordo com FIESP (2010), a água industrial é utilizada para:

- Consumo humano: atividades domésticas de contato humano direto (ambientes sanitários, vestiários, cozinhas e refeitórios, bebedouros, equipamentos de segurança);

- Matéria prima: incorporada ao produto final como: indústria de cervejas, refrigerantes, higiene pessoal, alimentos e fármacos;

- Fluído auxiliar: utilizada em diversas atividades com a intenção de substituir soluções químicas e compostos intermediários; 


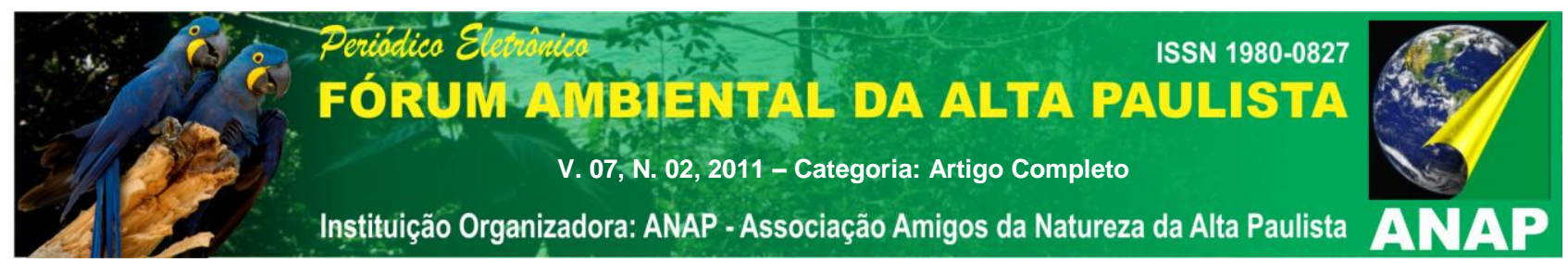

- Geração de energia: transformação da energia cinética, potencial ou térmica, mecânica e elétrica;

- Fluído de aquecimento ou resfriamento: utilizada como fluído de transporte de calor para remoção ou resfriamento de temperatura de misturas reativas ou outros dispositivos;

- Outros usos: combate a incêndio, rega de áreas verdes e incorporação em subprodutos gerados nos processos industriais nas fases sólida, líquida ou gasosa.

\subsection{Qualidade da água para reuso e indicadores de consumo na indústria}

Para FIESP (2010), a qualidade da água necessária aos diversos processos industriais depende do ramo de atividade e capacidade de produção, podendo ser utilizada em diferentes níveis de qualidade.

Tomaz (1998) concorda com o autor acima, pois para ele a indústria em suas várias atividades não precisa de água potável para aquecimento de caldeiras, torres de resfriamento, processos industriais, regas de jardins, pátios e descargas sanitárias.

Segundo SEBRAE (2010), na maioria das vezes não existe informação sobre o nível mínimo de qualidade da água para uma atividade industrial o que pode causar dificuldade na identificação de oportunidades de reuso.

Tomaz (1998) também considera que não há normas internacionais que regulamentem a qualidade da água de reuso industrial.

A qualidade da água, de acordo com FIESP (2010), é definida em função de características físicas, químicas, microbiológicas e radioativas, variando para cada tipo de aplicação, entre elas estão:

- Consumo humano: deve ser potável, atendendo às normas de qualidade da água;

- Matéria prima: pode variar desde que não prejudique a saúde humana e a qualidade final do produto; 


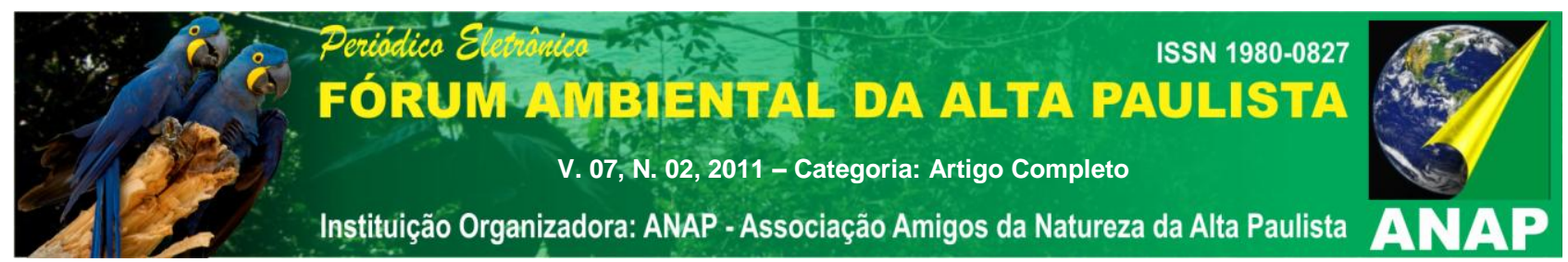

- Fluído auxiliar: deve apresentar alto grau se estiver em contato com o produto final e baixo se utilizada como concentração residual de agentes desinfetantes;

- Geração de energia: se utilizada para energia potencial ou cinética, a água pode ser captada diretamente de rio ou lago, mas para geração de energia térmica deve apresentar maior qualidade para não danificar os equipamentos de geração de vapor e os dispositivos de conversão de energia;

- Fluído de aquecimento ou resfriamento: para aquecimento a qualidade deve ser elevada, porém para o resfriamento pode ser inferior, levando em conta a conservação dos equipamentos.

De acordo com FIESP (2010), os indicadores de consumo da água na indústria avaliam a sua eficiência quanto ao uso, minimizam os impactos qualitativos, quantitativos, proporcionam a possibilidade de benchmarking entre as empresas de mesmo segmento e melhoria nos processos.

A indústria é responsável pelo uso de $22 \%$ da água doce disponível no mundo (AKATU, 2010).

Segundo Philippi; Roméro; Bruna (2004), em todo o mundo, a agricultura consome cerca de $69 \%$, a indústria $23 \%$ e o uso doméstico $8 \%$ de toda água disponível.

Mas para Dowbor; Tagnin (2005), quanto ao consumo, a agricultura utiliza $85 \%$, a indústria $10 \%$ e o uso doméstico $5 \%$.

O consumo por operário, segundo Tomaz (1998), é de 70 litros/dia, correspondendo a $16 \%$ do consumo total. Já o consumo na atividade é de $84 \%$. No total o consumo de cada empresa é de aproximadamente $1.087 \mathrm{~m}^{3} / \mathrm{dia}$.

A quantidade de água para o atendimento das atividades industriais dependerá do ramo de atividade, capacidade de produção, condições climáticas da região, método de produção, idade da instalação, prática operacional, cultura local, inovação tecnológica, investimentos em pesquisas, etc. Por isso em empresas do mesmo ramo a quantidade utilizada não é equivalente (FIESP, 2010).

Muñoz (2000 apud TSUTIYA, 2006), concorda que o volume de água na indústria varia de um segmento para outro, ainda que sejam semelhantes. 


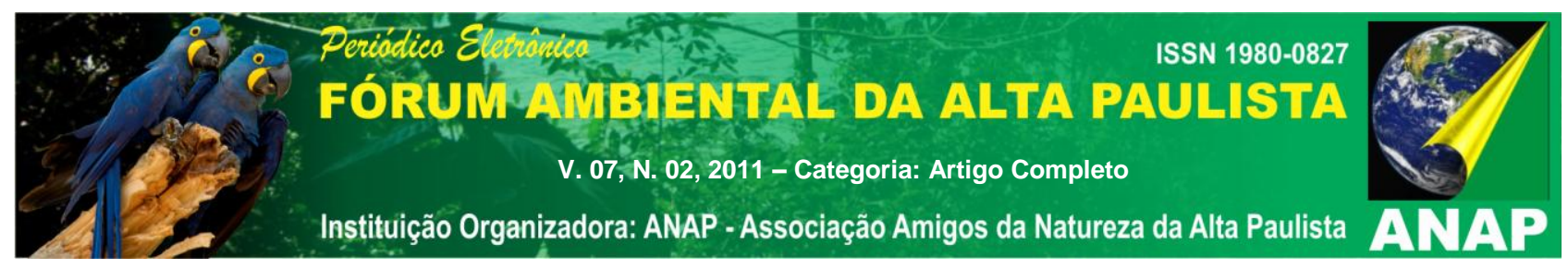

\subsection{As formas de reuso da água no setor industrial}

As categorias de reuso da água são potável e não potável. Segundo Westerhoff (1984 apud MANCUSO; SANTOS, 2003), o reuso potável pode ser direto ou indireto. Direto quando o esgoto recuperado por meio de tratamento é diretamente reutilizado no sistema de água potável. Já o indireto, passa por tratamento para depois ser despejado na coleção de águas superficiais ou subterrâneas.

De acordo com Braga et al.(2005), o reuso direto não passa por um tratamento prévio antes de ser colocado no sistema de distribuição de água como ocorre no reuso indireto em que os resíduos somente são diluídos no corpo hídrico após tratamento.

De acordo com Westerhoff (1984 apud MANCUSO; SANTOS, 2003), reuso não potável pode ser empreendido em atividades agrícolas, industriais, recreacionais, domésticas, manutenção de vazões, aqüicultura e recarga de aqüíferos subterrâneos. Geralmente é empregado em atividades de resfriamento, irrigação de áreas verdes e produção de insumos (USP, 2010).

De acordo com os autores citados no Quadro 1, algumas formas de reuso da água no setor industrial são:

\begin{tabular}{|c|l|}
\hline AUTORES & \multicolumn{1}{|c|}{ FORMAS DE REUSO } \\
\hline USP (2010) & \multicolumn{1}{|c|}{ Reuso planejado } \\
\hline SABESP (2010) & $\begin{array}{l}\text { É coordenado pela Organização das Nações Unidas (ONU) e pela } \\
\text { Organização Mundial da Saúde OMS, tendo como objetivos: proteger a } \\
\text { saúde pública, manter integridade dos ecossistemas e usar de forma } \\
\text { sustentável a água. }\end{array}$ \\
\hline Mancuso; Santos, (2003) & $\begin{array}{l}\text { É uma forma de reuso que exige um sistema de tratamento de acordo com } \\
\text { os padrões necessários para o novo uso da água. }\end{array}$ \\
\hline Mancuso; Santos, (2003) & $\begin{array}{l}\text { É o uso planejado de esgotos tratados para finalidades como: irrigação, uso } \\
\text { industrial, recarga de aqǘfero e água potável. }\end{array}$ \\
\hline Mancuso, Santos, (2003) & $\begin{array}{l}\text { Ocorre quando a água usada em atividades diversas é reutilizada de forma } \\
\text { diluída. }\end{array}$ \\
\hline Mancuso; Santos, (2003) & $\begin{array}{l}\text { Quando os efluentes são descarregados depois de tratados nos corpos } \\
\text { d'água superficiais ou subterrâneos. }\end{array}$ \\
\hline USP (2010) & Tem como objetivo usá-la de forma controlada para adquirir algum benefício. \\
\hline USP (2010) & Reuso indireto não planejado \\
\hline
\end{tabular}




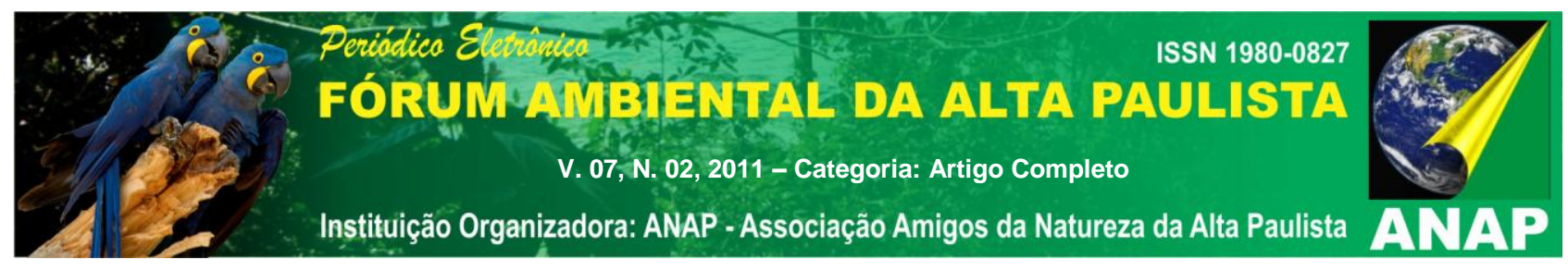

\begin{tabular}{|c|l|}
\hline Mancuso; Santos, (2003) & \begin{tabular}{l} 
meio ambiente de maneira não planejada. \\
\hline É um subproduto, pois após ser jogada no meio ambiente será diluída e \\
reuso.
\end{tabular} \\
\hline Mancuso; Santos, (2003) & $\begin{array}{l}\text { É o reuso praticado internamente às instalações industriais que tem como processos de purificação para ficar em condiçóes de } \\
\text { objetivo economizar água e controlar a poluição. }\end{array}$ \\
\hline USP (2010) & Ocorre antes de ser descarregada em um sistema de tratamento. \\
\hline Mancuso; Santos, (2003) & $\begin{array}{l}\text { É efetuado por companhias municipais ou estaduais que fornecem esgotos } \\
\text { tratados para as indústrias que por sua vez pagam pelo tratamento dos } \\
\text { mesmos, sendo uma possibilidade de reuso viável em localidades que } \\
\text { tenham um grande número de empresas do segmento próximas. }\end{array}$ \\
\hline SEBRAE, (2010) & $\begin{array}{l}\text { Trata-se do uso de efluentes tratados provenientes das concessionárias de } \\
\text { tratamento. }\end{array}$ \\
\hline Mancuso; Santos, (2003) & $\begin{array}{l}\text { Um meio pelo qual as empresas estimulam o reuso da água a partir de } \\
\text { possibilidades internas, reduzindo assim o consumo de uma forma geral. }\end{array}$ \\
\hline Braga et al., (2005) & $\begin{array}{l}\text { Esse tipo de reuso é muito incentivado devido à redução de custos que } \\
\text { proporciona. }\end{array}$ \\
\hline SEBRAE, (2010) & $\begin{array}{l}\text { Concorda com os autores acima que é o reuso de efluentes tratados ou não } \\
\text { e que são resultados da atividade da própria empresa. }\end{array}$ \\
\hline
\end{tabular}

Quadro 1: As formas de reuso da água no setor industrial

Fonte: Coelho; Oliveira; Yafushi; Pimenta Júnior (2011)

Por meio do Quadro 1 é possível observar que há diversas formas de reuso da água a disposição das indústrias, cabe, portanto a cada uma escolher aquela que melhor se adapte às suas atividades para que assim possa ser aceita e otimizada de maneira que leve a ela benefícios e ao mesmo tempo proporcione manutenção dos recursos hídricos e dos seres aquáticos, deixando as águas limpas para o abastecimento das cidades.

\subsection{Benefícios competitivos para o setor industrial por meio do reuso da água}

De acordo com os autores citados no Quadro 2, alguns benefícios que agregam valores competitivos ao setor industrial por meio do reuso da água são: 


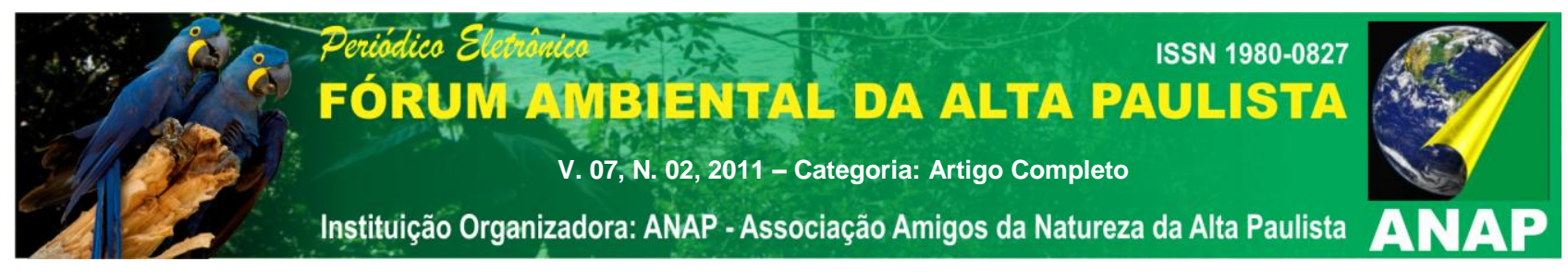

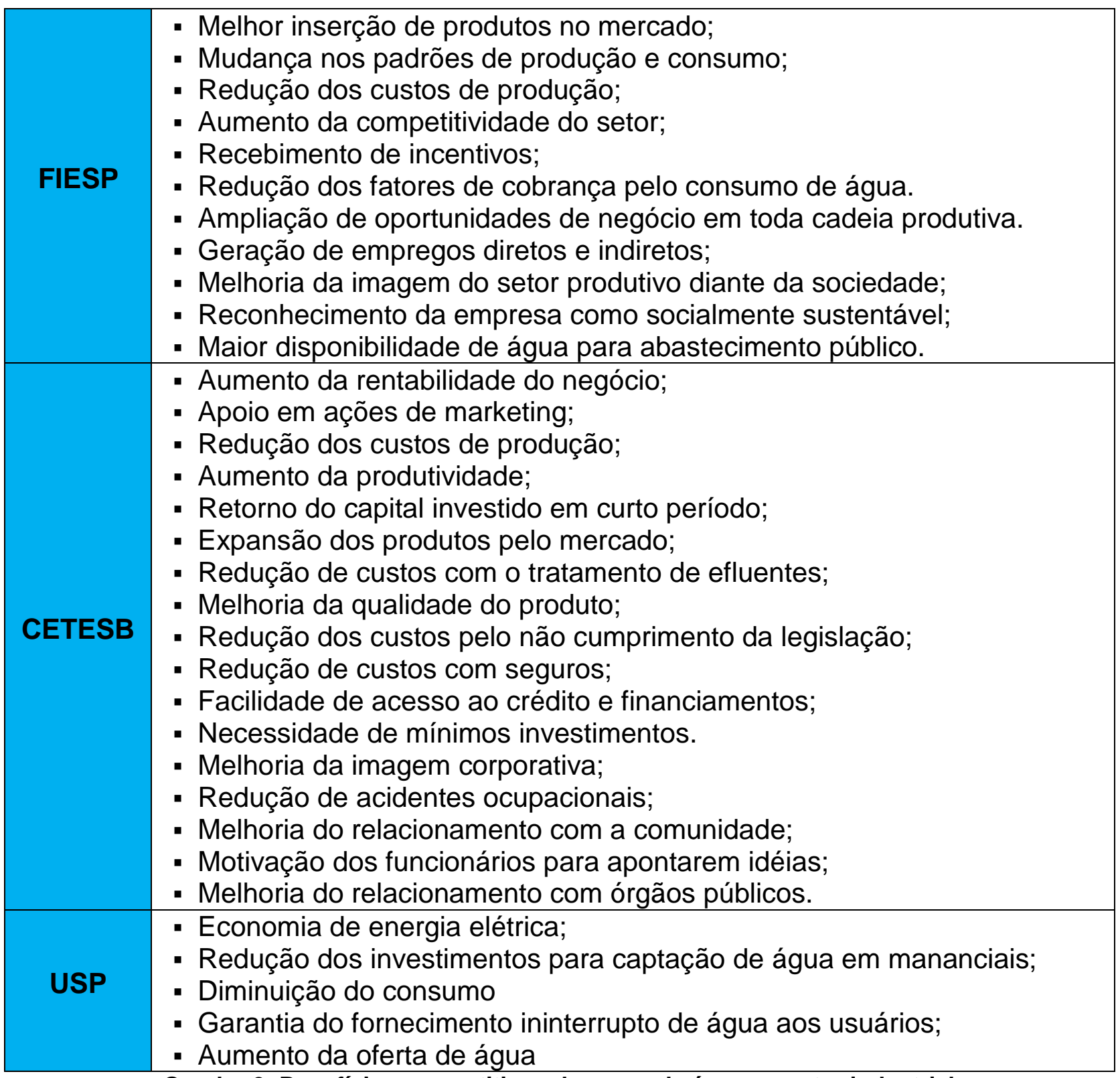

Quadro 2: Benefícios competitivos do reuso da água no setor industrial

Fonte: Coelho, Oliveira; Yafushi; Pimenta Júnior (2011)

Por meio do Quadro 2 é possível observar que as empresas industriais que reusam a água podem obter benefícios competitivos, possibilitando uma maior inserção no mercado em que atua, maior aceitação dos produtos e economia com relação aos custos da água utilizada no mês, adquirindo assim boa impressão por parte da sociedade e governo, o que a levará ao sucesso empresarial, pois as pessoas atualmente estão aderindo cada vez mais produtos de empresas ambientalmente sustentáveis. 


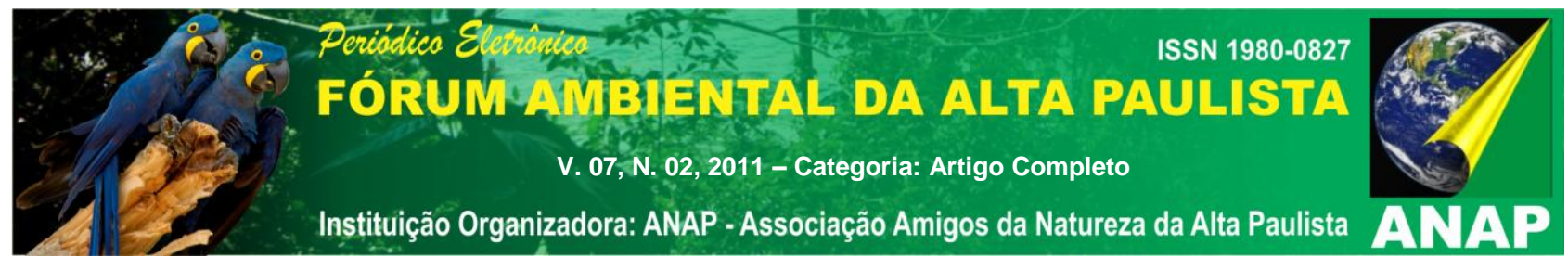

As questões ambientais atualmente constituem uma oportunidade de mercado, onde os consumidores estão cada vez mais preocupados com o processo produtivo dos bens que adquirem. Assim as empresas do ramo industrial devem utilizar-se da sustentabilidade como forma de vencer seus concorrentes.

A água, por ser um recurso essencial já escasso na natureza deve ter seu uso otimizado. Por isso o reuso mesmo que para outros fins que não seja o produtivo entra como opção para as empresas desse ramo preocupadas em preservar a manutenção desse recurso no meio ambiente.

São diversas as formas de reuso existentes á disposição das empresas, basta que elas escolham aquele que melhor se adapte as suas atividades.

Por meio do reuso, as empresas industriais como um todo podem obter benefícios econômicos, aumentando com isso sua competitividade no mercado, pois passaram a demonstrar que são socialmente responsáveis, adquirindo assim uma boa imagem por parte dos consumidores, fornecedores, governantes e sociedade em geral.

\section{REFERÊNCIAS}

BRAGA, B. et al. Introdução à engenharia ambiental. 2. ed. São Paulo: Pearson, 2005.

BRITO, F. A; CÂMARA, J. B. D. Democratização e gestão ambiental: busca do desenvolvimento sustentável. Petrópolis, Rio de Janeiro: Vozes, 1998.

CERVO, A. L.; BERVIAN, A. Metodologia científica. 5. ed. São Paulo: Prentice Hall, 2002.

CETESB. Reuso da água gera economia para as empresas e vantagens ambientais. Disponível em: <http://cetesb.sp.gov.br/reuso da água>. Acesso em: 22 out. 2010.

DOWBOR, L.; TAGNIN, R. A. Administrando a água como se fosse importante: gestão ambiental e sustentabilidade. São Paulo: SENAC, 2005.

FIESP. Conservação e reuso da água. Disponível em: <http:// www.fiesp.com.br/ conservação e reuso da água> Acesso em: 20 ago. 2010. 


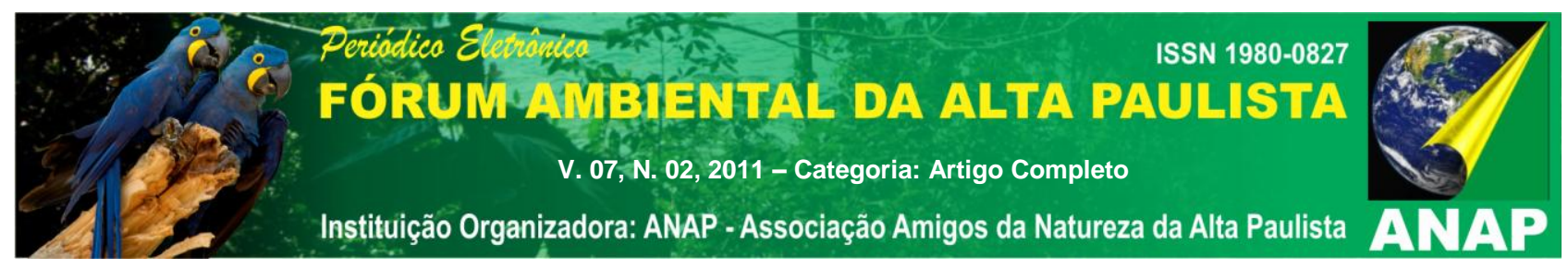

INSTITUTO AKATU. Setores industrial e agropecuário são campeões no consumo da água. Disponível em: <http://www.akatu.org.br>. Acesso em: 22 out. 2010.

MANCUSO P. C. S.; SANTOS H. F. Reuso da água. São Paulo: Manole, 2003.

MOURA, L. A. A. Qualidade e gestão ambiental. 3. ed. São Paulo: Editora Juarez de Oliveira, 2002.

PHILIPPI, A. Jr.; ROMÉRO, M. A.; BRUNA, G. C. Curso de gestão ambiental. São Paulo: Manole, 2004.

SABESP. Água de reuso. Disponível em: <http://www.sabesp.com.br> Acesso em: 20 ago. 2010.

SEBRAE. Resíduos e dejetos. Disponível em:

<http://www.sebrae.com.br/setor/agroenergia/o-setor/residuos-e-dejetos/o-que-e>. Acesso em: 23 de ago. 2011

TOMAZ, P. Conservação da água. São Paulo: Poli, 1998.

TSUTIYA, M. T. Abastecimento de água. 3. ed. São Paulo: Departamento de engenharia hidráulica e sanitária da escola politécnica da Universidade de São Paulo, 2006.

USP. Gestão da água. Disponível em: <http://pcc.usp.br/água>. Acesso em: 22 out. 2010. 